\title{
COMPARISON OF EFFICACY OF EPLEY MANOEUVRE AND VESTIBULAR SEDDATIVE IN POSITIONAL VERTIGO
}

\author{
Muhammad Sohail Babar Niazi, Khawar Kamal*, Zaheer Ul Hassan, Aisha Qaiser**, Shahid Farooq Khattak, Muhammad Tahir** \\ Combined Military Hospital Peshawar/National University of Medical Sciences (NUMS) Pakistan, *Combined Military Hospital Gujranwala, **Fauji Foundation \\ Hospital, Peshawar Pakistan, ${ }^{* * *}$ Combined Military Hospital Malir/National University of Medical Sciences (NUMS) Pakistan
}

\section{ABSTRACT}

Objective: To carry out the comparison of the effectiveness of Epleys manoeuvre and Vestibular Sedative in the management of benign paroxysmal positional vertigo.

Study Design: Quasi experimental study.

Place and Duration of Study: Department of ENT, Combined Military Hospital Peshawar, from Jul 2019 to Dec 2020.

Methodology: The study was conducted on 60 patients who were diagnosed Benign Paroxysmal Positional Vertigo by Dix Hallpike test. The patients were divided into 2 groups of 30 each. Group A was treated with vestibular sedative and group B was treated with Epleys manoeuvre. The examination of all patients was done on day 3, day 7 and day 14 and the results were documented.

Results: The study revealed that the 30 cases which were managed by Epleys manoeuvre, 27 cases were completely symptom free after 14 days. Meanwhile from the 30 patients who were treated by oral vestibular sedation, only 5 patients had total recovery on $14^{\text {th }}$ day. Chi square test was used to compare the results. The results showed that Epleys manoeuvre has greater efficacy in the treatment of Epleys man oeuvre than vestibular sedative.

Conclusion: Epleys manoeuvre is more effective for the management of benign paroxysmal positional vertigo than vestibular sedative.

Keywords: Benign Paroxysmal Positional Vertigo, Epleys Manoeuvre, Vestibular sedative.

How to Cite This Article: Niazi MSB, Hassan ZU, Qaiser A, Khattak SF, Tahir M. Comparison of Efficacy of Epley Manoeuvre and Vestibular Seddative in Positional Vertigo. Pak Armed Forces Med J 2021; 71 (Suppl-3): S437-439. Doi: https://doi.org/10.51253/pafmj.v1i1.7927

\footnotetext{
This is an Open Access article distributed under the terms of the Creative Commons Attribution License (https://creativecommons.org/licenses/by-nc/4.0/), which permits unrestricted use, distribution, and reproduction in any medium, provided the original work is properly cited.
}

\section{INTRODUCTION}

Benign paroxysmal positional vertigo (BPPV) is a frequent presentation in ENT OPDs. ${ }^{1,2}$ In BPPV the patient suffers from short and severe brief episodes of vertigo triggered by change of the head position. ${ }^{3}$ BPPV is caused by the displacement of otoconia from the saccule into the semicircular canals. ${ }^{4}$ It generally occurs between the ages of 50-70 years. ${ }^{5}$ Most of the patients with head injury after trauma develop symptoms of BPPV. ${ }^{6}$

The BPPV episode occurs when change of head position occurs. ${ }^{6}$ Characteristically violent vertigo of brief duration occurs once the patient is rolled towards the side with pathology. Severe nausea and vomiting may also be the associated features. ${ }^{7}$ This commonly occurs with turning in bed or changing position. DixHallpike manoeuvre is used to confirm the diagnosis of BPPV.

Epleys manoeuvre is widely used for the treatment of BPPV in several OPD settings..$^{8}$ Many setups employ vestibular sedative for the treatment of BPPV.

Correspondence: Dr Muhammad Sohail Babar Niazi, Department of ENT, Combined Military Hospital Peshawar Pakistan
In many patients of Benign Paroxysmal positional vertigo, the vertigo settles by itself. ${ }^{9}$ Several studies have revealed that Epleys manoeuvre is a very efficient manoeuvre in the management of BPPV. Moreover it is also noninvasive and takes very little time duration as well to execute. The vestibular sedative has been used in most of the clinics for settlement of symptoms of severe vertigo decades for last many decades. Vestibular seddatives reduce the intensity of vertigo and nystagmus evoked by a vestibular imbalance. These also reduce the associated motion sensitivity and motion sickness. Conventional vestibular suppressants consist of three major drug groups: anticholinergics, antihistamines and benzodiazepines.

\section{METHODOLOGY}

Inclusion Criteria: All patients of BPPV diagnosed positive by Dix Hall pike test.

Exclusion Criteria: Neck trauma in last 3 months diagnosed case of cervical spondylosis.

Proper consent was taken from the hospital ethical committee before the start of the study. All the patients in the study were included after complete informed consent. Detailed history was taken about 
the onset and duration of vertigo along with associated symptoms. The Dix Hall pike manoeuvre was used as the standard test for the confirmation of BPPV. The patients were divided into two groups by employing the random number tables. The patients in group A were managed by giving them per orally tab prochloperazine maleate (stemetil) mg 8 hourly daily for 14 days.

Epleys manoeuvre was used for the treatment of patients in group B. The manoeuvre began with the Dix Hallpike test. Once the nystagmus was settled, the patients head was kept in same position for 30 seconds. Now the head of the patient was moved in the exact opposite direction for three seconds. After that the new position was achieved by rolling the patient laterally. Once the nystagmus settled, then after 30 seconds the patient was quickly helped into sitting posture. In the last step the patient remained in this position for one minute. The examination of all patients was done on day 3, day 7 and day 14 and the results were documented.

All data was analyzed on Statistical Package for Social Sciences (SPSS) version 20. Age and gender were the variables which were put to analysis. For the numerical data the calculation of mean and standard deviation was performed while frequency \& percentage were employed for data regarding relief from vertigo. The two groups were compared by using the chi square test owing to the qualitative nature of the data. The significance level of $p$-value was considered as 0.05 or less.

\section{RESULTS}

Group A was treated with oral vestibular sedative. On the $3^{\text {rd }}$ day a total of 2 patients got relief from vertigo and showed negative Dix Hallpike test. On day 7, the Dix Hallpike test became negative for vertigo and nystagmus in further 2 patients. Finally on the day 14, 5 patients out of 30 had negative Dix Hallpike test showing relief from vertigo and nystagmus.

Epleys manoeuvre was employed for the management of patients in group B. At the $3^{\text {rd }}$ day 20 patients got relief from symptoms and Dix Hallpike test became negative. At the $7^{\text {th }}$ day same development was observed for further 5 patients. At the $14^{\text {th }}$ day 28 patients from a group of 30 got relief from symptoms and showed negative Dix Hallpike test. Chi square test was employed for the comparison of the two groups. The calculation of $P$ value was done. It showed to be lesser than 0.05 on all days of the study. Therefore the conclusion was made that the Epleys manoeuvre is more effective as compared to vestibular sedative in treating BPPV.

The age of the patients included in the study was in the range from 30 years to 60 years with a mean age incidence of 41.24 years with a standard deviation of 7.05. In group A of oral sedative 11 were females while 19 were males. In group B (Epleys group) 16 were females while 14 were males. In group B 3 patients (10\%) had feeling of nausea during the Epleys manoeuvre. In a total of 30 patients in group A 2 patients $(6.6 \%)$ had hearing loss and 3 patients $(10 \%)$ had tinnitus. In a total of 30 patients in group B 4 patients (13.3\%) had hearing loss and 2 patients $(6.6 \%)$ had tinnitus.

Table: Treatment outcome on day 14.

\begin{tabular}{|c|c|c|c|}
\hline \multirow[b]{2}{*}{$\mathrm{n}=60$} & \multicolumn{2}{|c|}{$\begin{array}{l}\text { Dix Hallpike Test } \\
\end{array}$} & \\
\hline & $\begin{array}{c}\text { Negative (Relief } \\
\text { from vertigo and } \\
\text { nystagmus) }\end{array}$ & $\begin{array}{c}\text { Positive (No relief } \\
\text { from vertigo and } \\
\text { nystagmus) }\end{array}$ & \\
\hline $\begin{array}{l}\text { Group A } \\
\text { (Oral sedative) }\end{array}$ & $5(16.6 \%)$ & $25(83.4 \%)$ & 30 \\
\hline $\begin{array}{l}\text { Group B (Epley } \\
\text { manoeuvre) }\end{array}$ & $28(93.3 \%)$ & $2(6.6 \%)$ & 30 \\
\hline
\end{tabular}

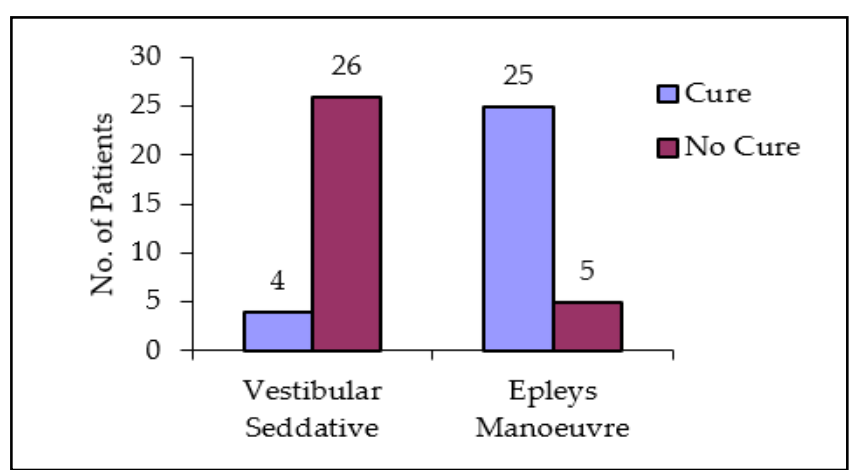

Figure-1: Outcome of vestibular sedative and epleys manoeuvre after 7 days $(n=60)$.

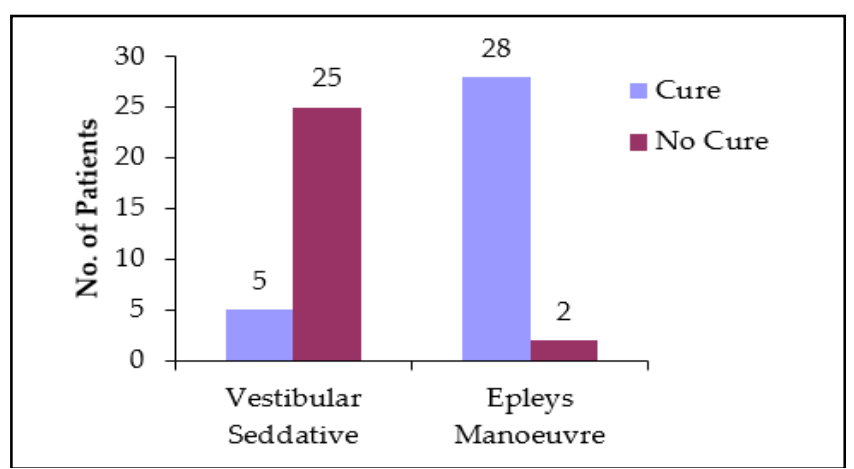

Figure-2: Outcome of vestibular sedative and epleys manoeuvre after 14 days $(n=60)$.

\section{DISCUSSION}

BPPV is a frequent problem encountered by clinicians in the outdoor patient department. Several stu- 
dies have been carried out to assess treatment of BPPV because it is a very prevalent condition. Prokopakis et $a l^{1}$ confirmed the effectiveness of Epleys manoeuvre treating the of patients with BPPV. Out of $93 \%$ of the patients became symptom free after Epleys manoeuvre hence revealing results very similar to our study.

Rashad et al ${ }^{10}$ also conducted a study showing the efficacy of Epleys manoeuvre in BPPV. The results were very similar to our study showing very high success rate of Epleys manoeuvre in the treatment of BPPV.

Pereira et $a l^{11}$, conducted a study in patients of BPPV treated with the Epley manoeuvre which showed a marked improvement in the quality of life of patients after Epleys manoeuvre. Ruckenstein et al ${ }^{12}$ showed $74 \%$ of patients becoming free from vertigo after Epleys manoeuvre.

Nakayama et al ${ }^{13}$ performed a study on the patients of BPPV. The results showed $92 \%$ efficacy of Epleys manoeuvre in the patients of BPPV. Richard et al also revealed similar results in his study on Epleys manoeuvre. Local studies conducted in Pakistan have also been conducted and shown the role of Epleys manoeuvre in BPPV. ${ }^{14,15}$ A comprehensive study was conducted by Pospeich et al ${ }^{1}$ about the role of various canalith repositioning manoeuvres including Epleys manoeuvre. It was shown to be highly effective in the management of BPPV as shown in other studies as well ${ }^{16-18}$. We showed even better cure rates from Epleys manoeuvre than Pospeich in this study.

\section{CONCLUSION}

Epleys manoeuvre is more effective in the treatment of BPPV than vestibular sedative.

\section{Conflict of Interest: None.}

\section{Authors' Contribution}

MSBN: Conceived the main idea, developed study design, KK: Statistical analysis, ZUH: Manuscipt drafting and bibliography, AQ: Helped in data interpratation, SFK: Research supervisor, MT: Developed study tool, literature survey.

\section{REFERENCES}

1. Prokopakis EP, Chimona T, Tsagournisakis M, Christodoulou P, Hirsch BE, Lachanas VA, et al. Benign paroxysmal positional vertigo: 10-year experience in treating 592 patients with canalith repositioning procedure. Lary 2005; 115(2): 1667-1671.

2. Von Brevern M, Radtke A, Lezius F. Epidemiology of benign paroxysmal positional vertigo: a population-based study. J Neurol Neur Psych 2007; 78(7): 710-715.

3. Coppo GF, Singarelli S, Fracchia P. Benign paroxysmal positional vertigo: Follow-up of 165 cases treated by Semont's liberating maneuver. Acta Otorhinolaryngol Ital 1996; 16(1): 508-512.

4. Nuti D, Nati C, Passali D. Treatment of benign paroxysmal positional vertigo: No need for postmaneuver restrictions. Otolaryngol Head Neck Surg 2000; 122(2): 440-444.

5. Epley JM. The canalith repositioning procedure: For treatment of benign paroxysmal positional vertigo. Arch Otolaryngol 1993; 119(2): 450-454.

6. Richard $\mathrm{W}$, Bruintjes TD, Oostenbrink $\mathrm{P}$, van Leeuwen RB. Efficacy of the Epley maneuver for posterior canal BPPV: a longterm, controlled study of 81 patients. Ear 2005; 84(1): 22-25.

7. Gaur S, Awasthi S, Bhadouriya S, Saxena R, Pathak V, Bisht M. Efficacy of epley's maneuver in treating BPPV patients: A prospective observational study. J Otolaryngol 2015; 15(2): 487-489.

8. Uz U, Uz D, Akda Gl, Çelik O. Efficacy of epley maneuver on quality of life of elderly patients with subjective BPPV. J Int Adv Otol 2019; 15(3): 420-424.

9. Von Brevern M, Seelig T, Radtke A, Tiel-Wilck K, Neuhauser H, Lempert T. Short-term effi cacy of Epley's manoeuvre: A doubleblind randomised trial. J Neurol Neur Psych 2006; 77(2): 980-982.

10. Rashad UM. Long-term follow up after Epley's manoeuvre in patients with benign paroxysmal positional vertigo. J Laryngol Otol 2009; 123(2): 69-74.

11. Pereira AB, Santos JN, Volpe FM. Effect of Epley's maneuver on the quality of life of paroxismal positional benign vertigo patients. Braz J Otorhinolaryngol 2010; 76(2): 704-708.

12. Ruckenstein MJ. Therapeutic efficacy of the epley canalith repositioning maneuver Laryng 2001; 111(1): 940-945.

13. Nakayama M, Epley JM. BPPV and variants: improved treatment results with automated, nystagmus-based repositioning. Otolaryngol Head Neck Surg 2005; 133(2): 107-109.

14. Mazoor T, Niazi, SB. Efficacy of Semont manoeuvre versus Epley manoeuvre in Benign Paroxysmal Positional. Pak Armed For Med J 2011; 61(2): 70-73.

15. Niazi SB, Ali M, T Muhammad. Benign paroxysmal positional vertigo; efficacy of vestibular sedative versus Epley manoeuvre. Professional Med J 2012; 19(4): 336-340.

16. Beynon GJ. A review of management of benign paroxysmal positional vertigo by exercise therapy and by repositioning manoeuvres. Br J Audiol 1997; 31: 11-26.

17. Richard W, Bruintjes TD, Oostenbrink P, van Leeuwen RB. Efficacy of the epley maneuver for posterior canal BPPV: a longterm, controlled study of 81 patients. Ear 2005; $84: 22-5$.

18. Pérez Vázquez P, Manrique Estrada C, Muñoz Pinto C, Baragaño Río L, Bernardo Corte MJ, Suárez Nieto C. Treating benign paroxysmal positional

19. vertigo with the canalith repositioning maneuver of Epley. Our experience. Acta Otorrinolaringol Esp 2001; 52: 193-8. 